Annals of Glaciology 61985

(C) International Glaciological Society

\title{
MOVEMENTS OF MARGINAL PACK ICE OFF THE OKHOTSK SEA COAST OF HOKKAIDO
}

\author{
by
}

NoBUO ONO

Institute of Low Temperature Science, Hokkaido University, Sapporo, Japan 060

\section{ABSTRACT}

Movement of pack ice off the Okhotsk Sea coast of Hokkaido was investigated using combinations of sea ice radar photographs and Landsat MSS imageries. The sea ice radar network, consisting of three C-band (5.54 $\mathrm{GHz}$ ) radar stations, covers an area of about $60 \mathrm{~km}$ across and $250 \mathrm{~km}$ along the coast. As radar echoes display not the shape of ice floes but the roughness of the ice field, the shapes of floes were drawn on a radar photograph overlaid upon a simultaneous Landsat

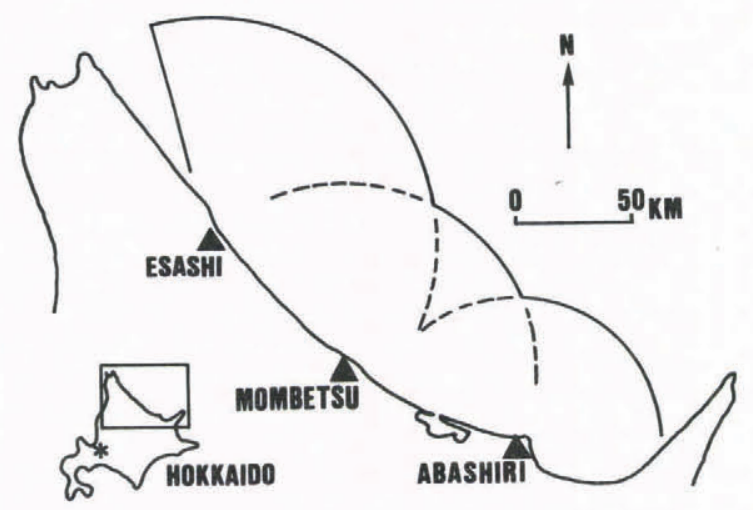

Fig.1. The coverage of the sea ice radar network. imagery. Each floe was then traced on the sequential photographs of radar display. The path of each floe frequently indicated a trochoidal oscillation of 18-hour period which is close to the inertial period of this area. Such paths were examined as representing the motion of inertial circle transported upon a long-period movement. The parameter $\mathrm{v} / \mathrm{U}$ indicates the magnitude of meandering movement of an ice floe within the inertial period, where $v$ is the circumferential velocity of inertial circle motion and $U$ is the average velocity of a main drift in the inertial period. Values of $v / U$ were obtained in a wide range from 0.4 to 8.3 for 18-hour trochoidal paths sampled.

\section{INTRODUCTION}

The Sea of Okhotsk $\left(1.53 \times 10^{6} \mathrm{~km}^{2}\right)$ is covered with pack ice up to about $80 \%$ of the sea at the end of February in the normal winter. Even in the southernmost part of the sea, that is, off the Okhotsk Sea coast of Hokkaido, sea ice forms from January to March. Pack ice originating in the north appears near the coast of Hokkaido in January and stays until April. Movement of pack ice in this area was investigated by combining sea ice radar photographs and Landsat MSS imageries.

\section{THE SEA ICE RADAR NETWORK}

The radar network consists of three unmanned stations near Esashi, Mombetsu and Abashiri along the Okhotsk Sea coast of Hokkaido. Radar antennas situated

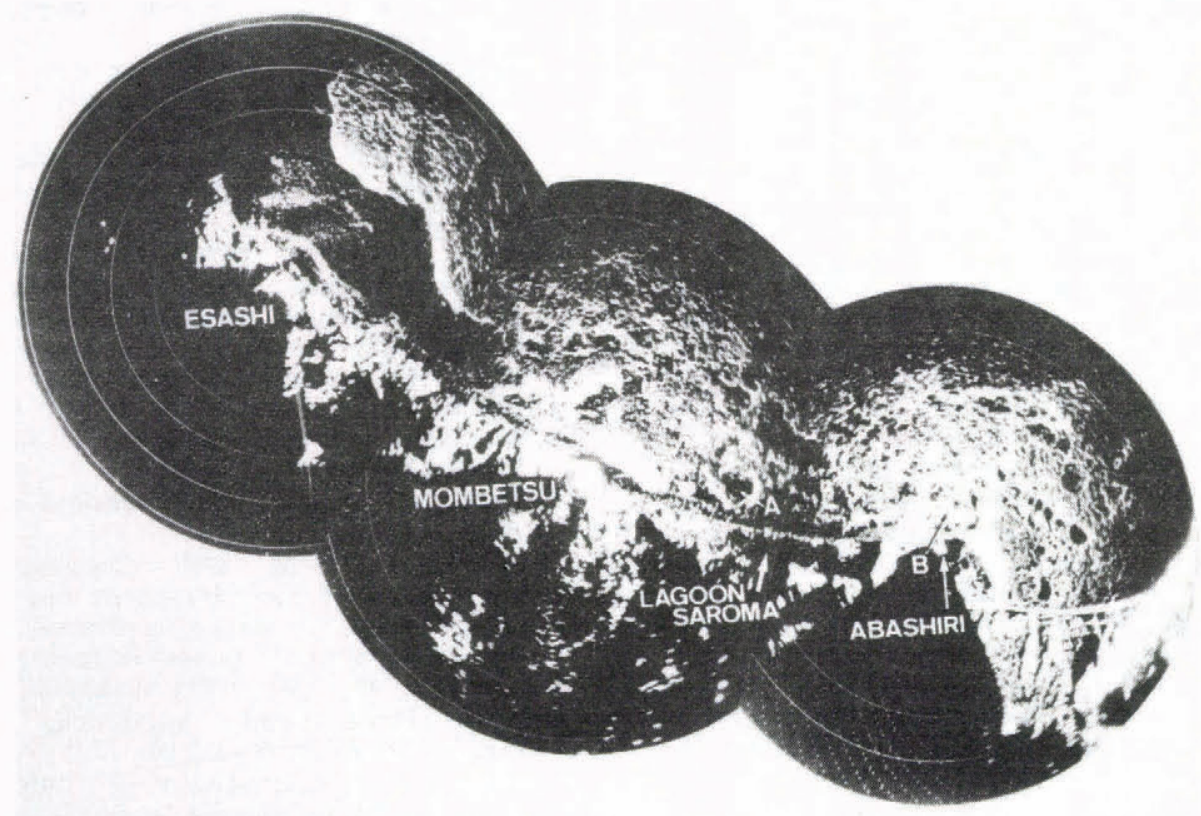

Fig.2. A composite photograph of three radars at 09 JST (00 GMT) on 19 March 1979. A: a smooth surface floe; B: a rough surface floe. 
on the hill-tops at elevations of $433 \mathrm{~m}, 300 \mathrm{~m}$ and 200 $\mathrm{m}$, respectively, are remote-controlled by radio from the Sea Ice Research Laboratory in Mombetsu city. The radar network covers an area of about $60 \mathrm{~km}$ across and $250 \mathrm{~km}$ along the coast (Figure 1). Radar echoes returned from the pack ice are transmitted also by radio from the hill-top stations to the laboratory.

The radar is characterized by the $\mathrm{C}$-band in the frequency of $5.54 \mathrm{GHz}$, beam width of one degree and pulse width one micro second, having therefore a resolution of $150 \mathrm{~m}$ at distance. By use of this radar, the distribution of pack ice is observable successively in any weather and even in the dark.

\section{A COMBINATION STUDY OF RADAR AND LANDSAT} IMAGERIES

A composite photograph of three radar screens at 00 GMT on 19 March 1979 is shown in Figure 2. Simultaneous Landsat imagery is shown in Figure 3 on the same scale. A comparison shows fairly good correspondence between the two on the shape of ice edges, especially off Esashi.

As radar echoes display not the shape of ice floes but the roughness of the ice field, it is difficult to interpret the shape and position of an individual floe on the radar photograph. For example, the large lagoon Saroma was covered with level ice at that time (Figure 3): the echo from the ice was however absent on the

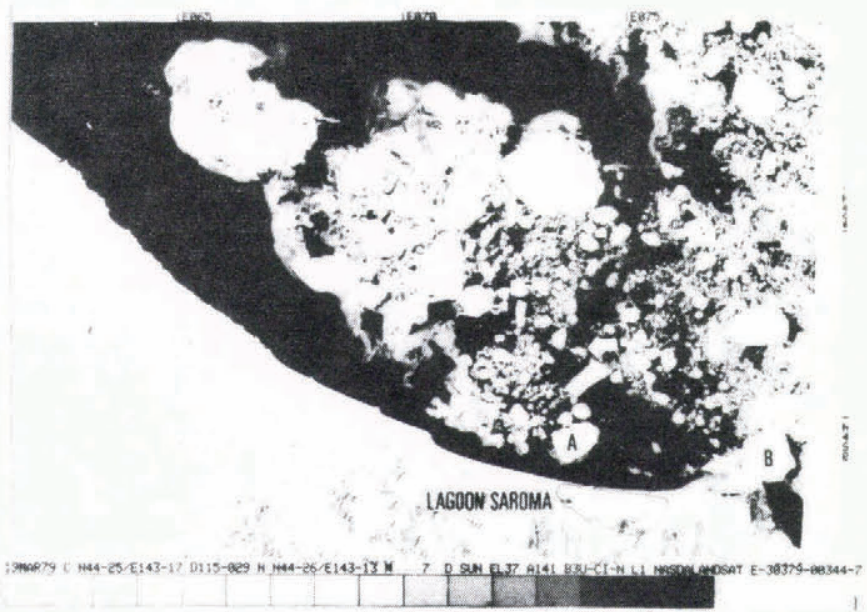

Fig.3. The Landsat MSS-7 imagery almost simultaneous with Fig.2. A: a smooth surface floe; B: a rough surface floe.

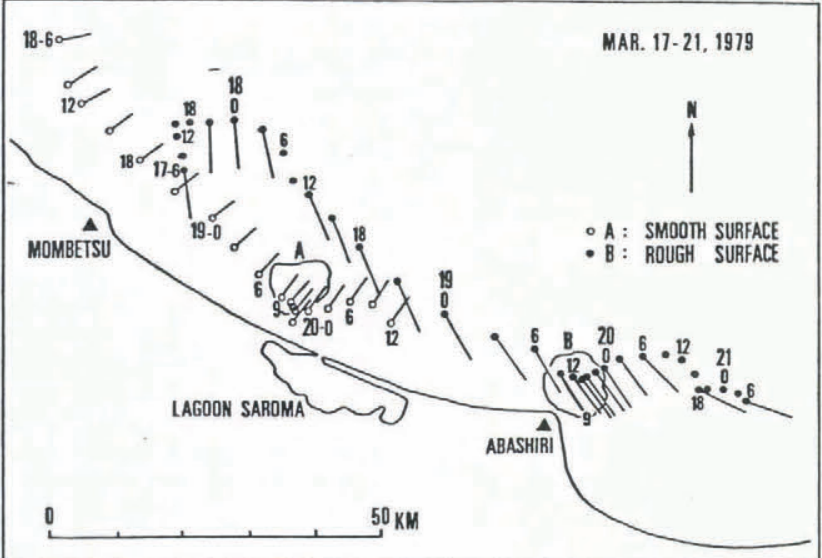

Fig.4. Movements of ice floes on the sequential radar photographs. Numerals attached are the date and time (JST) of each photograph. Each stick indicates the direction of a base-line drawn on the ice-floe echoes. Open circles: a smooth surface floe (A); solid circles: a rough surface floe (B). radar display (Figure 2). The echo from the centre of a large floe, (A in Figure 3), about $12 \mathrm{~km}$ in diameter off the west side of the lagoon was also absent (Figure 2). It is therefore interpreted as an ice floe with a smooth surface.

The shapes of floes were drawn by tracing from a radar photograph overlaid on the simultaneous Landsat imagery. Each floe was then followed on the sequence of radar photographs taken several days before and after the day of combined imageries. Drift and rotation of each floe were obtained (Figure 4). The floes represented as $A$ and $B$ in the figures are selected as samples of the different surface roughness of ice which is estimated from the intensity of the radar echo. These floes drifted southeastwards along the coast with distinct meanders and a slight rotation.

\section{TROCHOIDAL PATHS OF PACK ICE}

Movement of pack ice is clearly visualized in a time-lapse motion picture of the radar display. Even though the complicated movement of a pack-ice field is observed in the motion picture, the path of each ice floe frequently indicates a simple curve resembling a trochoid. The period of one trochoidal path was estimated as 17 to 18 hours, which is closely equal to the inertial period of this area.

The trochoidal path of an ice floe is expressed as:

$$
\begin{aligned}
f x & =U \theta-v \sin \theta \\
f y & =U-v \cos \theta \\
\theta & =2 \pi t / T
\end{aligned}
$$

where $T$ is the inertial period, $f$ is the Coriolis parameter, $v$ is the circumferential velocity of inertial circle motion, and $U$ is the average velocity of the

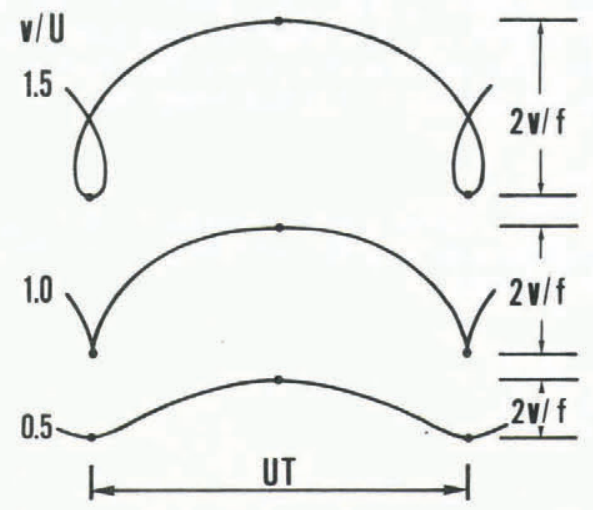

Fig.5. Trochoidal paths of the inertial period motion.

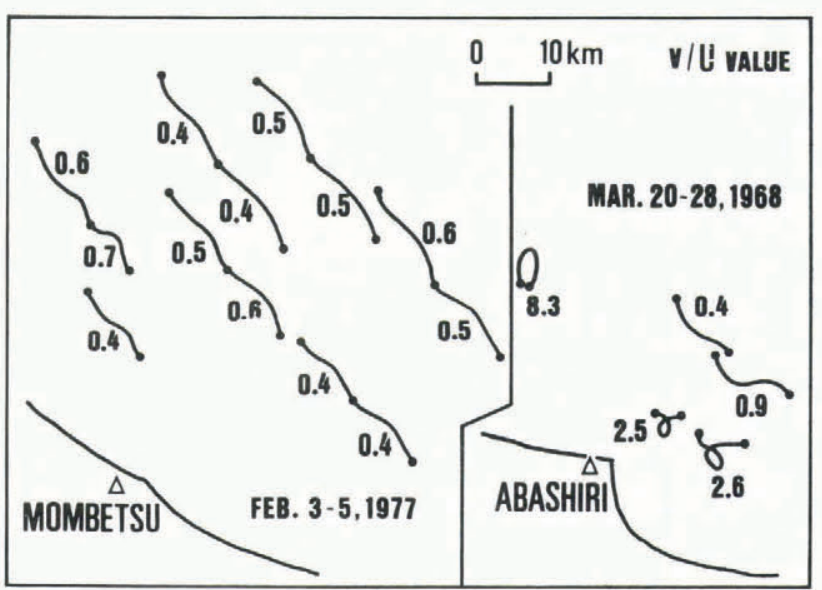

Fig.6. Samples of the 18-hour trochoidal paths with $v / U$ values. 
center of the circle moving along the $x$-axis taken toward the main drift direction (Ono 1978). Velocities $v$ and $U$ are obtained respectively from the amplitude and the wavelength of the trochoidal path (Figure 5).

Examples of the trochoidal path of ice floes are shown in Figure 6 with values of $v / U$. As the velocities $U$ and $v$ correspond to the main drift and the meandering movement respectively, the parameter $v / U$ indicates the magnitude of meandering movement of an ice floe within the inertial period. The values of $v / U$ were obtained in a wide range from 0.4 to 8.3 for 18 -hour trochoidal paths sampled as shown in Figure 6.

Mesoscale eddy motions larger than the inertial motion are often observed in the time-lapse motion picture of the radar display. It is obviously seen from the satellite images that these eddies constitute some branches of large eddy patterns of a pack-ice field devloped in the southern Okhotsk Sea.

\section{CONCLUDING REMARKS}

The movement of marginal pack-ice field of $f$ the Okhotsk Sea coast of Hokkaido was investigated. Characteristics of pack ice, such as the shape, size and surface roughness were obtained by combining sea ice radar photographs and Landsat imageries.

Each of the ice floes, the shape of which was drawn on the radar photograph by simulataneous Landsat imagery, was traced on the sequentia photographs of the radar display. The path of each floe indicated frequently the trochoidal motion oscillating in a period of 17 to 18 hours. Such paths were examined as resulting from the inertial motion which is transported by the main drift. The parameter $v / U$, obtained in the range from 0.4 to 8.3 for the 18 -hour trochoidal paths sampled, indicates the magnitude of meandering movement within the inertial period.

\section{ACKNOWLEDGEMENTS}

The author thanks the staff of the Sea Ice Research Laroratory for help in processing the radar data, and also the National Space Development Agency of Japan for the use of Landsat imageries.

\section{REFERENCE}

Ono N 1978 Inertial period motions of drifting sea ice (in Japanese with English summary). Low Temperature Science A37: 107-113 